\title{
PREVALENCE OF CYBERBULLYING AND TRADITIONAL BULLYING AND THEIR RELATIONSHIP TO SELF-ESTEEM AMONG HEARING-IMPAIRED ADOLESCENTS
}

\author{
Mohammad Ahmed Hammad ${ }^{1 *}$, Huda Shaaban Awed $^{2}$ \\ ${ }^{1 *}$ Faculty of Education, Najran University, Kingdom of Saudi Arabia; ${ }^{2}$ Special Education Department, Najran University, \\ Kingdom of Saudi Arabia and Faculty of Education, Assiut University, Egypt. \\ Email: ${ }^{1 *}$ hammadeg73@yahoo.com, ${ }^{2}$ hudaeg2010@yahoo.com
}

Article History: Received on $29^{\text {th }}$ January 2020, Revised on $16^{\text {th }}$ September 2020, Published on $27^{\text {th }}$ September 2020

\begin{abstract}
Purpose: bullying among students with disabilities, especially hearing impairment adolescents is a neglected problem in most Arab countries, including Saudi Arabia.
\end{abstract}

Objective: This study aimed to investigate the prevalence of cyberbullying and traditional bullying and their relationship to self-esteem in adolescent students in southern Saudi Arabia.

Methods: Three questionnaires (cyberbullying, traditional bullying, and self-esteem) were used to assess the studied parameters. They were distributed to 81 students with hearing impairment (10th and 12th grade), $(\mathrm{M}=18.64, \mathrm{SD}=1.06)$.

Main Findings: Findings indicated that $56.4 \%$ were exposed to traditional victimization, $52.9 \%$ bullied others at school, $44.6 \%$ were not exposed to victimization, while $47.1 \%$ had not participated. Concerning cyberbullying, $90.5 \%$ were not exposed to cyber-victimization, and $94.2 \%$ had not participated in cyber-bullying. Males were more exposed to traditional and cyber-victimization than females; besides, they were significantly higher in self-esteem than females. We found a statistically significant correlation between traditional victimization and traditional bully. We also found a statistically significant correlation between self-esteem and both traditional victimization and bully, while no significant correlation between self-esteem and cyber-bully/victims.

Novelty/Originality of this study: Additional studies are needed to compare the traditional bullying and cyberbullying, and its relationship to psychological variables among Saudi children with disability and typically developing peers. Moreover, there is an urgent need for evolving prevention and intervention programs to overcome bullying and its negative effects among individual and society.

Keywords: Cyberbullying, Traditional Bullying, Self-Esteem, Adolescents, Hearing Impairment, Saudi Arabia. INTRODUCTION

Bullying in schools constitutes a substantial problem for students worldwide (Hwang et al., 2018). In Saudi Arabia, bullying has been addressed recently (AlBuhairan et al., 2016). Jeeluna National Study, which addresses the needs of teenagers in Saudi Arabia, found that $25 \%$ of students reported bullying in middle and high schools (AlBuhairan et al., 2015). Bullying is defined as a form of aggressive behavior, perpetrated by a more powerful individual or group against a less powerful victim (Carney \& Merrell, 2001; Corcoran et al., 2015; Smith et al., 2003; Smith et al., 1999). Hence, there is spacious consensus on the specific criteria for traditional bullying, namely (a) intent to cause harm or distress (i.e. hitting, verbally assaulting face-to-face, etc.) or indirect (i.e. rumours, gossip, etc.) (Corcoran et al., 2015) (b) repetition of the behaviour over time (i.e., more than once with the possibility of multiple occurrences) (Greene, 2006; Hwang et al., 2018), and (c) Power imbalance between the victim(s) and bully (ies) (i.e., bullying includes a genuine or perceived power inequity between the bully and the victim) (Campbell, 2005; Corcoran et al., 2015). In Parallel with the development of technology, cyber-bullying has taken the place of traditional bullying through technological tools, such as computers, smartphones, social networking sites, email, online forums, personal websites, and game sites (Agatston et al., 2007; Harper, 2019). Hence, has become cyberbullying a chronic and serious public health problem, especially for adolescents, because It aims to harm, threaten, intimidate, or embarrass others psychologically and socially (Carrington et al., 2017; Corcoran et al., 2015; Olweus, 2012). Furthermore, Cyberbullying allows vulnerable children or children with disability to bully their powerful peers, as they are usually not (Hillsberg \& Spak, 2006).

Concerning the consequences of Cyberbullying and traditional bullying, In many relevant studies, there is agreement on the negative consequences of cyberbullying and traditional bullying, for example, on the bully or victim, such as mental health problems, low self-esteem, anxiety, depression, drug use, sleep disorders, abuse, and behavioral problems (Carrington et al., 2017; Harper, 2019; Humphrey \& Hebron, 2015; Olweus, 2012). As noted, the researches results on cyberbullying and traditional bullying among students with disability have confirmed several cases of verbal and physical abuse, as well as social rejection. Students with disability have more frequent targets of bullying than their peers without disability ( 
\& Awed, 2016; Maiano et al., 2016; Víllora et al., 2019).

Many previous studies indicated that children and adolescents between 10 and 30\% participated in bullying (Corvo, 2010; Hale et al., 2017), where 15-20\% of students in grades 3 to 6 have been bullied and violent from their peers, While students

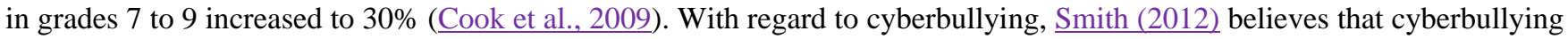
generally appears much less frequent than traditional bullying; perhaps a quarter to a third of bullying. For the hearing impaired's problem, very few studies have addressed bullying among students with hearing impaired, as mentioned by Hadjikakou and Panayiotis (2012), who reviewed the longitudinal literature network and manual review of contributions that have led to bullying among students with hearing loss over the past 34 years. 13 studies have indicated that the minimum research has been published with a focus on bullying among students with hearing impaired; therefore this field needs to be examined. (Bauman \& Pero, 2010; Weiner et al., 2013) found that between 17-32.5\% of children and adolescents with hearing impairments are involved in bullying. In addition, Bauman and Pero (2010) conducted a study on 30 students with hearing impairment in secondary schools. The results indicated that $27 \%$ of students with hearing impairment were involved in traditional bullying, $10 \%$ were involved in cyberbullying, and $14 \%$ were victims of cyberbullying in their lives. Weiner et al. (2013) Tested 812 students with hearing impairment (grades 3-12) in 11 U.S. schools; the results indicated that the students with hearing impairment were involved in bullying three times higher than their typically developing peers. Besides, (Raskauskas \& Modell, 2011; Weiner et al., 2013) suggest that students with hearing impairment than their typically developing students. This is due to the lower of social and communication skills, self-esteem, emotional control, and support and encouragement than their typically developing peers (Theunissen et al., 2014). Furthermore, others have attempted to identify why bullies of typically developing children targeting children with hearing impairment, Previous studies indicated that typically developing children believe that the children with hearing impairment is an easy target, cannot communicate with others, and even defend themselves. Some studies suggest that males are higher than females to engage in cyberbullying and traditional bullying (Huang \& Chou, 2010; Twardowska-Staszek et al., 2018). While other studies have indicated that females are higher than males (Cénat et al., 2014). Whereas many studies do not report any gender differences at all (Calvete et al., 2010; Dembo et al., 2019)

Self-esteem has a substantial impact on cognition, motivation, empathy, and behavior, also a good indicator of mental health. (Rosenberg (1965) He described self-esteem as a favorable or unfavourable attitude toward the self. It reflects how valuable and efficient a person feels. Self-esteem is an assessment of a person's situation as he thinks when a person has positive attitudes toward himself, self-esteem is high, and vice versa (Hammad, 2016; Smith, 1997). This positive or negative assessment, conducted in the light of self-esteem, can have a tremendous impact on daily life (Butt et al., 2019). Positive self-esteem acts as a defensive agent for negative effects, boosting productivity, mental health, life satisfaction, selfawareness, and social interaction (Olweus, 2012). However, negative assessment and self-esteem act as a precipitating factor for social and mental problems such as substance abuse, crime, poor health, violence, anxiety, and aggression (Lei et al., 2019; Mann et al., 2004; Smith, 2012). Most researchers regard low self-esteem as an influencer for both traditional and cyberbullying (Aslan, 2011; Hesapçioğlu et al., 2018). According to the social bonding theory, individuals' behavior is not expected to be compatible with social norms because a lack of self-esteem weakens social bonding. Thus, traditional and cyberbullying occur (Patchin \& Hinduja, 2010). Many studies indicate that bullying has been associated with lower levels of adolescent self-esteem, depression, and social rejection (Kowalski \& Limber, 2013; Lee et al., 2019). Furthermore, previous studies of bullying and self-esteem indicate that bullying victims tend to be less self-esteem than no victims (Olweus, 2012; Patchin \& Hinduja, 2010). This may be because falling as a victim leads to low self-esteem, or those with low self-esteem are likely to be targeted as victims by the bullies (Brewer \& Kerslake, 2015). The relationship between bullying offending and self-esteem is relatively inconsistent (S. Hinduja \& J. Patchin, 2010). (Koh \& Wong, 2017; Salmivalli et al., 1999) indicate that the bullies have higher self-esteem than non-bullies (Koh \& Wong, 2017; Salmivalli et al., 1999), while (Olweus, 2012; Wolke \& Sapouna, 2008) indicate bullies have lower self-esteem than non-bullies. Moreover, studies have shown that there are no formidable differences between self-esteem and groups of bullies and non-bullies (Palermiti et al., 2017). Olweus (2012) reported that many of the allegations about the negative effects of cyberbullying in the media are greatly exaggerated. Hence, the negative effects of traditional bullying are more consequential than cyberbullying. For example, if a student is exposed to cyberbullying and traditional bullying, the additional impact of cyberbullying seems negligible. Concerning self-esteem for hearing impairment children and young people, many studies indicate that they suffer from a decline of self-esteem concept, where disability directly affects a person's self-esteem, leading to depression, loneliness, and peer rejection (Teresa V Crowe, 2003; Kogovšek, 2015). Furthermore, hearing impairment faces many challenges, such as speech and language delay, and communication problems, that affect self-esteem (Bowman, 2018; Pinquart \& Pfeiffer, 2015)

\section{Cyberbullying and Traditional bullying in Saudi Arabia}

Cyberbullying and Traditional bullying have received appreciable attention in many countries, especially in the West (e.g., Europe, the United States, Australia, and Canada) (e.g. Brack \& Caltabiano, 2014; Brewer \& Kerslake, 2015; Hinduja \& 
Patchin, 2019). At the same time, the term bullying is relatively new to the Arab region, especially, Saudi Arabia with published studies on this phenomenon dating back to 2008. It is safe to say this topic is under-researched (Almuneef, 2016). But it has recently received greater attention. For example, Fleming and Jacobson's 2009 study carried out 19 countries with 104,614 students; five were from the Middle East and North Africa: United Arab Emirates, Morocco, Oman, Jordan, and Lebanon. the bullying ratio in these countries was between $20 \%$ and $44 \%$, higher than the overall rate of the 19 countries. The bullying reached $18 \%$ in a survey of 18,000 people living in 24 countries, including Saudi Arabia (Peluchette et al., 2015). Almuneef et al. (2014), found 12.5\% of adults living in Riyadh, Saudi Arabia have been victims of childhood, and males were higher than females (28.2\% vs. 14.7\%). Yet AlBuhairan et al. (2016) found 25\% and (AlBuhairan et al., 2017) found $26 \%$ of adolescents had subjected to traditional bullying, and boys were more engaged than girls (27.1\% vs. $22.7 \%$ ), and 33\% of physical violence in the last year. Moreover, they were associated with many mental disorders such as anger, depression, poor trust, and low mental health. In the primary school questionnaire about peer interaction between three countries, Egyptians ( $\mathrm{N}=361$ ), Saudi Arabian ( $=350$ ), and USA (270) children, (Hussein, 2010) found that the level of bullying of boys/girls in Egypt and Saudi Arabia is higher than Americans, and boys were higher than girls in the three cultures, but both had a similar level of victimization. Another study was among 268 students aged 6-10 years at an international school in Riyadh, (81\%) admitted they had been bullied either by their teachers or parents, (48\%) in the playground, while $36.7 \%$ in the classroom and $14.9 \%$ on the school bus. The bullying was higher among the best male students; there was a statistically significant relationship between exposure to school bullying and being bully (Alrokban et al., 2019). Furthermore, studies have identified certain variables that may influence students' increased prevalence of bullying. For example, (Nouran, 2015) conducted a qualitative study to determine the scope of bullying, by examining how familiar are teachers with it and what types of bullying in Saudi elementary schools. Findings showed that less than half of teachers knew about and that those who knew did not know how to deal with, concerning cyberbullying in Saudi Arabia. Some results indicate that cyberbullying is low among school adolescents, for example, Al-Zahrani (2015) examined cyberbullying among (287) university students and (27\%) admitted to cyberbullying at least once or twice in the past, respecting, the prevalence rate of cyberbullying and traditional bullying among adolescents with disabilities. Especially, Hearing impairment in Saudi Arab has not received much attention in Saudi Research. Thus, it is clear that further research is needed to address the paucity of studies regarding the prevalence rate cyberbullying and traditional bullying among Saudi hearing-impaired adolescents. In addition, more research is needed to examine the psychology effects (i.e., Self-esteem) of the perpetration of bullying and cyberbullying behaviors. Hence, findings between male and female adolescents in bullying are mixed.

\section{Research questions}

The literature review revealed the proliferation of cyberbullying and traditional bullying among youth. In many states, especially among children and adolescents in schools (Brewer \& Kerslake, 2015 in UK; Choi et al., 2019 in the United

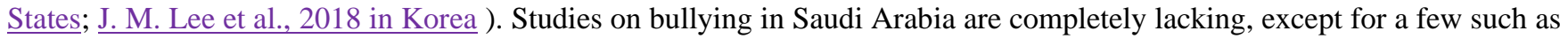
(Al-Zahrani, 2015; AlBuhairan et al., 2017; AlBuhairan et al., 2016; AlBuhairan et al., 2015; Almuneef et al., 2014). Furthermore, there are no studies focusing on adolescents with hearing impairment. It would be fruitful to investigate the prevalence of cyberbullying and traditional bullying among adolescents with Hearing impairment in Saudi Arabia, as well as the relationship between bullying and self-esteem. based on this, we asked the following questions:

RQ1: What is the cyberbullying and traditional bullying prevalence rate among adolescents with Hearing impairment in Saudi Arabia?

RQ2: Is there will be a statistically significant correlation between cyberbullying and traditional bullying and self-esteem?

RQ3: Are there any gender differences in cyberbullying and traditional bullying?

\section{METHOD}

\section{Participants}

The sample was convenience composed of (81) hearing impairment Adolescents (10th and 11th grade), in six integration secondary schools, in the cities (Najran, Asir, Jazan) in the south of Saudi Arabia. Student's ages ranged from 17 to 20 years $(\mathrm{M}=18.64, \mathrm{SD}=1.06)$. Degree of hearing impairment, (HL > $25 \mathrm{~dB}$ PTA in the better ear) and no other impairments. Over half $(59.25 \%)$ had a profound or severe disability, $(37.03 \%)$ had severe/profound, $(3.7 \%)$ had a moderate or mild disability. The hearing level was verified through official school reports. Hearing-impaired students were partially integrated with So, the more bullying happens between adolescents with hearing impairment and typically developing children in the same school, but students with Hearing impairment in Separate Buildings Learn from their typically developing peers. They also may be unable to communicate and interact with them. Therefore, this study was limited to the hearing impaired. 


\section{Procedure}

The author received the letter of approval for the Department of Private Education and the School Ethics for Integration. Six secondary schools were selected to participate, at the invitation of schools, all adolescent students with hearing loss were invited to participate in the research. All parents were informed of the study and signed for approval. Participants confirmed their responses were confidential. To ensure that the standards' instructions are understood, written in preferred methods to communicate with the hearing impaired; hearing impairment were selected from two copies of this Questionnaire: The first copy consists of questions written in Arabic, The second copy was written in Arabic, and translated in sign language by a qualified hearing impairment instructor. In addition, all Questionnaire was translated from English into Arabic and then translated by bilingual experts, while maintaining the same meaning as the original Questionnaire.

Our analytic survey study using three Questionnaire: The self-esteem questionnaire (Rosenberg, 1965); The European Bullying Intervention Project Questionnaire (EBIPQ; Brighi et al., 2012); The European Cyberbullying Intervention Project Questionnaire (ECIPQ; Del Rey et al., 2015) for both genders. Students were given a clear and simple definition of selfesteem, cyberbullying, and traditional bullying behaviors before they responded to the Questionnaire. It took approximately from September to December 2018 to gather the required data. The sign language interpreter is provided during the application of the Questionnaire.

\section{The Questionnaire}

\section{The Rosenberg Self-Esteem Scale (Rosenberg, 1965)}

The Rosenberg Self-Esteem Scale (Rosenberg, 1965) was a well-established, reliable, and honest for measuring of selfesteem. Students with Hearing impairment were assessed from the self-assessment scale. The Scale consists of four responses from 0 (strongly disagree) to 3 (strongly agree), it also includes ten terms, five are positive (e.g. On the whole, I am satisfied with myself) and five are negative (e.g. At times I think I am not good at all). Scores were ranged from zero to thirty, between 15 to 20 were at the normal range. Scores above 20 degrees indicate high self-esteem, and scores below 15 degrees low self-esteem. The Scale had been tested for reliability and validity; whether typically developing children or children with hearing impairment (Brack \& Caltabiano, 2014; Teresa V. Crowe, 2003; Kobosko et al., 2018; Rosenberg, 1965). The Cronbach's alpha estimate obtained for the present sample was 0.76 .

\section{The European Bullying Intervention Project Questionnaire (EBIPQ; Brighi et al., 2012)}

This Questionnaire was used to assess bullying behavior (face to face). It consists of 14 items, divided into two parts; Part I, containing of 7 items describing aspects of victimization. For instance, (Someone has hit me; kicked me, pushed me, or insulted me). Part II, containing of 7 items related to aggressive behavior. For instance, (I threatened someone; I hit, kicked or pushed someone). All items have a Likert-type design, with a score between 0 and 4 , where 0 means never and 4 always, referring to a time interval of the last two months. The internal consistency of the original Questionnaire was (.82) for the victimization portion, (.74) for the aggressive portion, and (.85) for all Questionnaire. The Cronbach's alpha value estimate obtained for the present sample was (total= .80; victimization .76; aggressive $=.74$ ).

\section{The European Cyberbullying Intervention Project Questionnaire (ECIPQ; Del Rey et al., 2015)}

This Questionnaire was used to assessed Cyberbullying; it consists of 22 items, divided into two parts; Part I, containing 11 items that describe aspects related to cyber-victimization. For instance, (Someone has told me bad words or insulted me using email or SMS; someone has hacked into my account and pretended to be me), Part II, containing of 11 items is related to cyber-aggression, For instance, (I have threatened someone through SMS or messages on the internet; I have posted personal information about someone on the internet). All items have a Likert-type design, with a score between 0 and 4 , where 0 means never and 4 always, referring to a time interval of the last two months. The internal consistency of the original Questionnaire was (.96) for the cyber-victimization portion, (.93) for the cyberbullying portion, and (.98) for overall Questionnaire. The Cronbach's alpha value estimate obtained for the present sample was (total = .84; cybervictimization.79; cyberbullying = .77).

\section{Data analysis}

To analyze the data of this work, Coding and data analysis were carried out using the SPSS Statistics V18 software to perform the statistical analysis. The significance level for p-values was set at 0.05 . Percentages, frequency, means, and standard deviation were calculated for all variables Cyberbullying (cyber-victimization and cyber-aggression), traditional bullying (victimization and aggression), and Self-Esteem. T-tests were conducted for all variables with respect to Gender (male and female). In addition, the correlation coefficient analyses were performed to identify the association between variables in a study. 


\section{RESULTS}

\section{Cyberbullying and traditional bullying prevalence rates}

To answer the research first question, descriptive statistics were used. Results indicated that $(56.4 \%$; $n=45)$ were exposed to traditional victimization (i.e., victim only); $(52.9 \%$; $n=43)$ bullied others at school (i.e., bully only), $(44.6 \%$; $n=36)$ were not exposed to victimization, While $(47.1 \%$; $\mathrm{n}=38$ ) had not participated. (See Table 1 for the prevalence of involvement in traditional bullying, i.e., once or twice, once a week and two to three times a month or more). Concerning cyberbullying, $(90.5 \% ; n=73)$ indicated that had not been exposed to cyber-victimization (i.e., the victim only). In addition, $(94.2 \% ; n=76)$ indicated that had not participated in cyber-bullying (i.e., bully only), as with traditional bullying, prevalence rates of involvement in cyberbullying in Table 1.

Table 1: Prevalence of traditional bullying and cyberbullying by $(\mathrm{HI})(\mathrm{N}=81)$.

\begin{tabular}{lcclllll}
\hline \multicolumn{1}{c}{ Categories } & Never & $\begin{array}{c}\text { Once or } \\
\text { twice }\end{array}$ & $\begin{array}{c}\text { Once or } \\
\text { twice a } \\
\text { month }\end{array}$ & $\begin{array}{c}\text { Once a } \\
\text { week } \\
\text { approxim } \\
\text { ately }\end{array}$ & $\begin{array}{c}\text { More } \\
\text { than once } \\
\text { a week }\end{array}$ & M SD & \\
\hline traditional bullying & & & & & & & \\
\hline victimization & $36(44.6 \%)$ & $14(17.3 \%)$ & $\begin{array}{l}10 \\
(12.4 \%)\end{array}$ & $\begin{array}{l}11 \\
(13.6 \%)\end{array}$ & $\begin{array}{l}12 \\
(14.8 \%)\end{array}$ & 9.13 & 8.87 \\
\hline aggression & $38(47.1 \%)$ & $12(14.8 \%)$ & $7(8.7 \%)$ & $13(16.2 \%)$ & $\begin{array}{l}11 \\
(13.6 \%)\end{array}$ & 6.5 & 8.40 \\
\hline cyberbullying & & & & & & & \\
\hline cyber-victimization & $73(90.5 \%)$ & $4(5 \%)$ & 1 & $2(2.5 \%)$ & $1(1.24 \%)$ & 0.81 & 1.19 \\
\hline cyber- bullying & $76(94.2 \%)$ & $3(3.7 \%)$ & $1(1.24)$ & $1(1.24)$ & $0(0 \%)$ & 1.45 & 2.13 \\
\hline
\end{tabular}

\section{Gender differences in cyberbullying, traditional bullying and Self-Esteem}

Table 2 shows that males were more exposed to traditional victimization and bully than females. In addition, there was a statistically significant difference between male and female in cyber-victimization and bully rates also observed, despite their low participation level in cyberbullying among Hearing impaired students, this is illustrated from the findings that males were more exposed to cyberbullying than females. In addition, although the average males score were within the normal selfesteem range (17.30) degrees, and females tend to have significantly normal Self-Esteem levels (14.85) degrees, According to the Rosenberg Self-Esteem Scale (Rosenberg, 1965), but the results showed that males have higher levels of self-esteem than females.

Table 2: Gender differences in traditional bullying, cyberbullying and Self-Esteem

\begin{tabular}{lccccccc}
\hline \multicolumn{10}{c}{ Male (42) } & \multicolumn{7}{c}{ Female (39) } & & & \\
\hline scale & M & S & M & S & T & df & $\boldsymbol{p}$ \\
\hline traditional bullying & & & & & & & \\
\hline victimization & 9.30 & 9.10 & 2.51 & 2.08 & 4.55 & 79 & 0.01 \\
\hline bullies & 6.52 & 8.65 & 1.46 & 1.66 & 3.59 & 79 & 0.01 \\
\hline cyberbullying & & & & & & & \\
\hline cyber-victimization & 0.85 & 1.09 & 0.15 & 0.53 & 3.62 & 79 & 0.01 \\
\hline cyber- bullies & 1.04 & 1.54 & 0.17 & 0.38 & 3.40 & 79 & 0.01 \\
\hline Self-Esteem & 17.30 & 1.86 & 14.35 & 0.87 & 5.94 & 79 & 0.01 \\
\hline
\end{tabular}

\section{Correlation between cyberbullying, traditional bullying and Self-Esteem}

As shown in Table 3 which shows a statistically significant correlation between variables. We found a statistically significant correlation between traditional victimization and traditional bullying. In addition, there was no statistically significant correlation between the two forms of victimization and the two forms of bullying. Furthermore, there was a statistically significant correlation between self-esteem and both traditional victimization and aggression; on the contrary, there was no statistically significant correlation between self-esteem and both cyber-victimization and cyber-aggression. 
Table 3: The correlations between the traditional bullying, cyberbullying subscale, and Self-Esteem Scale.

\begin{tabular}{|c|c|c|c|c|c|}
\hline & Victimization & Aggression & Cyber-victimization & Cyber-aggression & Self-Esteem \\
\hline \multicolumn{6}{|l|}{ traditional bullying } \\
\hline victimization & & $0.89 * *$ & 0.18 & 0.19 & $0.26^{*}$ \\
\hline aggression & & & 0.19 & 0.14 & $0.40 * *$ \\
\hline \multicolumn{6}{|l|}{ cyberbullying } \\
\hline cyber-victimization & & & & $0.85 * *$ & 0.10 \\
\hline cyber-aggression & & & & & 0.11 \\
\hline Self-Esteem & & & & & \\
\hline
\end{tabular}

Note: $* \mathrm{p}<.05 . * * \mathrm{p}<.01 .(\mathrm{N}=81)$.

\section{Statistical analysis}

To analyze the data of this work, Coding and data analysis were carried out using the SPSS Statistics V18 software to perform the statistical analysis. The significance level for p-values was set at 0.05 . Percentages, frequency, means, and standard deviation were calculated for all variables Cyberbullying (cyber-victimization and cyber-aggression), traditional bullying (victimization and aggression), and Self-Esteem. T-tests were conducted to for all variables with respect to Gender (male and female). In addition, the correlation coefficient analyses were performed to identify the association between variables in a study.

\section{DISCUSSION}

Most researches on cyberbullying and traditional bullying focuses primarily on typically developing children at different stages of development, especially adolescence, but there is little research on bullying among people with disabilities, especially in the Arab world (Almuneef, 2016; Weiner et al., 2013). Indeed, it's not only bullying is a problem with Hearing impaired students, although they may be bullied as victims, but also negative consequences of this phenomenon for these students. To our knowledge, this is the first descriptive study on cyberbullying and traditional bullying among hearingimpaired students in Saudi Arabia. This study provides useful data on prevalence, traditional bullying, cyberbullying, and self-esteem. Results indicated that $56.4 \%$ were exposed to traditional victimization, $52.9 \%$ bullied others at school, which indicates that hearing-impaired students have high participation rates in traditional bullying as either victims or bullies. This due to the fact, that the disability has multiple negative consequences the characteristics of hearing impaired, thus making it characterized by aggression, violence, anger, hyperactivity, their need to satisfying immediate desires, and their inability to postpone them (Bauman \& Pero, 2010; Hadjikakou \& Panayiotis, 2012; Jani et al., 2020; Mulat et al., 2019). Such behaviors, make them a traditional bullied, whether it is a bully or victim (e.g., Carrington et al., 2017; Ghiamatyoon et al., 2016; Weiner et al., 2013). In addition, these students may have fewer friends. Therefore, lead to a low level of protection from bullying. These results are consistent with previous studies (Bauman \& Pero, 2010; Hwang et al., 2018; Weiner et al., 2013). Interestingly, results indicate that the hearing impairment students are significantly more traditional bullying than cyberbullying, we were surprised when the results demonstrated that lower rates of smartphone ownership among hearing impairment student. This may be attributed, in part, poor socioeconomic circumstances and low level of knowledge in students' families with hearing impaired, or they may not even be aware of the advantages (and risks) using technology on their children, This is also confirmed by (Bauman \& Pero, 2010). In addition, the Southern region are characterized by a cultural conservatism of traditions and customs, therefore, the children are born to moral obligation. As well as it may be a shame, they use electronic means, such as mobile or email to harm others.

The study results provide evidence of a statistically significant association between low self-esteem and traditional bullying

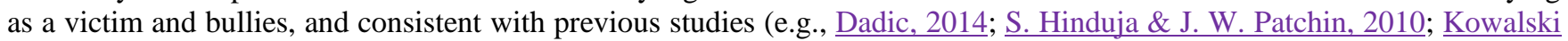
\& Limber, 2013). It was also noted that most hearing-impaired student-related research (e.g., Mousavi et al., 2017; Movallali et al., 2014) Indicate that these students may be constrained from others, because of communication problems that negatively affect others' understanding. In addition, they have low self-esteem, especially during social interaction with others. Then, seen as easy targets for victimization. Accordingly, Teachers and officials should take action to prevent, stop and respond to all forms of bullying, whether in school or electronic means of communication, because this directly affects the school climate and the students' luxury, concerning gender patterns in cyberbullying and traditional bullying among hearingimpaired students in Saudi Society. The results indicated that males are more likely than females to engage in cyberbullying and traditional bullying, more particularly, males were more likely to be traditional victimization and bully than females. Also, males were more likely to be cyber-bullying than females, females were less likely to be cyber-victimization than males, these results are consistent with some previous studies (Bauman \& Pero, 2010; Wang et al., 2019). This is partly due to the fact that Saudi is a masculinity society, as well as strongly influenced by cultural traditions. If males can express feelings like anger and revenge, they also can express emotions freely, even if they have a hearing impairment. In contrast, 
Parents exert much control over their females, due to the pervasive social shyness from having children with disability in Saudi society, especially if girl has a disability, many families hide their disabled daughters, fearing that their sister not to get married. In addition, their concerns that girls may be subjected to violence outside. Moreover, females are afraid to get into trouble with their peers, which makes school management summon their parents. Furthermore, Males can communicate with aliens, while girls cannot. With regard to the cyberbullying, girls fear unwanted messages or attacks others online than males, where they do not trust privacy guarantees and Internet safety, as well as female fear of parents when some of these problems arise. Also, males are highly skilled in technology than females (Barlett \& Coyne, 2014; Huffman et al., 2013).

These gender differences in self-esteem were observed, indicating that males are more self-esteem than females. As previously mentioned, this may be due to, origin and culture of the individual. Where Gender is considered by many to be a cultural phenomenon (J. Lee et al., 2018; Peplau et al., 1999; Wade et al., 2006). In addition, Gender is considered a social invention, encompassing rights, duties, and behavioral patterns, which appropriate for males and females. Generally, men still have a greater status and power than women (Teresa V. Crowe, 2003; Wade et al., 2006). As well, in Arab society, where young people are born and nurtured in a masculine society, especially Saudi Arabia, relies heavily on adolescent, and instill a lot of confidence. On the contrary, the girl does not get the same attention. In addition to, the Saudi family's ambition to be married her. While the adolescent is the holder of the surname and sponsor, all these roles give him a positive attitude toward himself.

Interestingly, despite young man with hearing impaired, providing families with social and emotional support positively affects self-esteem. On that basis, a young man with hearing impairment, who has the ability to develop and build good relationships with peers tends to have the highest self-esteem. These results are consistent with some previous studies (Teresa V. Crowe, 2003; Jambor \& Elliott, 2005; Peplau et al., 1999; Wade et al., 2006).

\section{CONCLUSIONS AND IMPLICATIONS}

Some conclusions and implications can be drawn from the results of this study. The well-being of children, adolescents with disabilities and hearing impairments, are indispensable for the development of any society. It is also one of the most paramount mental health points in Saudi Arabia. Cyberbullying and traditional bullying are tricky issues that have to be solved and addressed to overcome the negative impact on individuals and society. The main contribution of this study is provided a deeper understanding of the prevalence of traditional bullying compared to cyberbullying, and its relationship to self-esteem among students with hearing impaired. Cyberbullying and traditional bullying should not be considered a separate phenomenon. Instead, two sides of the same coin. Some current study results seem not to be a direct correlation between cyberbullying and traditional bullying; this may be attributed to the nature of the societies, where the hearing impairment live. Furthermore, the results highlighted the role of hearing impairment in bullying, and hearing-impaired students were exposed to bullying as victims. You have to take into consideration the education system and the structure surrounding the students. It is erroneous to blame the victim, or bully, and not to face the situation completely. Therefore, Saudi officials must integrate hearing impaired students with their peers properly. Indeed, Integration helps increase peer acceptance for students with hearing impaired; In addition, the integrated student acquires many academic, social, and functional skills compared to their non-integral peers. Therefore, instead of bullying which may occur between typically developing children and hearing impaired, or hearing impairment. These skills and activities will help to make positive and interactive friendships. In addition, the media should highlight the students with hearing impaired and represent them as part of the community. In order to reduce bullying in Saudi Arabia. School principals and officials could raise banners a campaign against bullying, and improved surveillance. Moreover, provide comprehensive demonstration programs and services that will equip the hearing impaired students with the necessary knowledge, attitude, and skills to become more aware of and positively treat bullying and its negative effects.

\section{LIMITATIONS OF THE STUDY}

This study provides some limitations. First, this study was conducted on a Saudi sample. Culture can be an important moderator about cyberbullying and bullying involvement. Therefore, we should be very cautious when disseminating the findings to other cultures. Second, despite the current study in Saudi Arabia, the base sample was drawn on one geographic location, the southern of Saudi Arabia. Therefore, they must be cautious in disseminating these results to other adolescent populations. Third, our study was cross-sectional. Therefore, the findings must be preliminary; Thus, Future studies should apply a prospective design that examines characteristics of hearing impairment victims and bullies, Cyberbullying and traditional bullying dynamics may be unique to this community, and other environmental factors. Fourthly, the results of this study are based solely on students' self-reports. Therefore, there may be some weaknesses. Teachers need to support hearingimpaired students to complete the Questionnaire; Thus, Students may have felt that their response could be separated, thus perhaps unwilling to respond faithfully. In addition, they may feel that their peers may see responses to the Questionnaire, although they have confirmed anonymity and confidentiality by the study. Accordingly, future studies should be included in other methods (i.e., observation, teacher reports, and peer reports). Despite these limitations, this was the first study to 
investigate the prevalence of cyberbullying, traditional bullying, and its relationship to self-esteem among hearing impairment adolescents in Saudi Arabia. Our results set a solid framework for future research.

\section{STATEMENTS ON OPEN DATA, ETHICS AND CONFLICT OF INTEREST}

a. Data can be accessed by contacting the author.

b. No agreements of any type were needed.

c. No conflict of interest declared.

\section{CO-AUTHORS CONTRIBUTION}

Mohammad Hammad was the main leader of the study, who organized the research and distributed roles and tasks, formulated a scientific hypothesis about "prevalence of cyberbullying and traditional bullying, and their relationship to self-esteem in adolescent students in southern Saudi Arabia.

Huda Awed collected analytical data and analyzed the existing literature on the research topic.

\section{ACKNOWLEDGMENTS}

Financial support from Deanship of Scientific Research, Najran University, Kingdom of Saudi Arabia, (NU/SHED/16/144) is gratefully acknowledged.

\section{REFERENCES}

1. Agatston, P. W., Kowalski, R., \& Limber, S. (2007). Students' perspectives on cyber bullying. Journal of Adolescent Health, 41(6), S59-S60. https://doi.org/10.1016/j.jadohealth.2007.09.003

2. Al-Zahrani, A. M. (2015). Cyberbullying among Saudi's Higher-Education Students: Implications for Educators and Policymakers. World Journal of Education, 5(3), 15-26. https://doi.org/10.5430/wje.v5n3p15

3. AlBuhairan, F., Abou Abbas, O., El Sayed, D., Badri, M., Alshahri, S., \& de Vries, N. (2017). The relationship of bullying and physical violence to mental health and academic performance: A cross-sectional study among adolescents in Kingdom of Saudi Arabia. International Journal of Pediatrics and Adolescent Medicine, 4(2), 61-65. https://doi.org/10.1016/j.ijpam.2016.12.005

4. AlBuhairan, F. S., Al Eissa, M., Alkufeidy, N., \& Almuneef, M. (2016). Bullying in early adolescence: An exploratory study in Saudi Arabia. International Journal of Pediatrics and Adolescent Medicine, 3(2), 64-70. https://doi.org/10.1016/j.ijpam.2016.01.002

5. AlBuhairan, F. S., Tamim, H., Al Dubayee, M., AlDhukair, S., Al Shehri, S., Tamimi, W., El Bcheraoui, C., Magzoub, M. E., De Vries, N., \& Al Alwan, I. (2015). Time for an adolescent health surveillance system in Saudi Arabia: findings from "Jeeluna". Journal of Adolescent Health, 57(3), 263-269. https://doi.org/10.1016/j.jadohealth.2015.06.009

6. Almuneef, M. (2016). Bullying in the Arab region: a journey from research to policy. Ending the torment: tackling bullying from the schoolyard to cyberspace, 139.

7. Almuneef, M., Qayad, M., Aleissa, M., \& Albuhairan, F. (2014). Adverse childhood experiences, chronic diseases, and risky health behaviors in Saudi Arabian adults: A pilot study. Child Abuse \& Neglect, 38(11), 1787-1793. https://doi.org/10.1016/j.chiabu.2014.06.003

8. Alrokban, A. H., Alzaidi, R. M., Alqahtani, S. A., Almoayad, F., \& Fiala, L. E. (2019). Bullying and its risk factors among elementary school children in Riyadh, Saudi Arabia. 6(6), 105-114.

9. Aslan, S. (2011). The analysis of relationship between school bullying, perceived parenting styles and self-esteem in adolescents. Procedia-Social and Behavioral Sciences, 30, 1798-1800. https://doi.org/10.1016/j.sbspro.2011.10.346

10. Barlett, C., \& Coyne, S. M. (2014). A meta-analysis of sex differences in cyber-bullying behavior: The moderating role of age. Aggressive Behavior, 40(5), 474-488. https://doi.org/10.1002/ab.21555

11. Bauman, S., \& Pero, H. (2010). Bullying and cyberbullying among deaf students and their hearing peers: An exploratory study. Journal of deaf studies and deaf education, 16(2), 236-253. https://doi.org/10.1093/deafed/enq043

12. Bowman, M. E. (2018). The grand challenges of social work: Deaf children in the child welfare system. Children and Youth Services Review, 88, 348-353. https://doi.org/10.1016/j.childyouth.2018.03.034

13. Brack, K., \& Caltabiano, N. (2014). Cyberbullying and self-esteem in Australian adults. Cyberpsychology: Journal of Psychosocial Research on Cyberspace, 8. https://doi.org/10.5817/CP2014-2-7

14. Brewer, G., \& Kerslake, J. (2015). Cyberbullying, self-esteem, empathy and loneliness. Computers in Human Behavior, 48, 255-260. https://doi.org/10.1016/j.chb.2015.01.073 
15. Brighi, A., Ortega, R., Scheitauer, H., Smith, P., Tsormpatzoudis, C., Barkoukis, V., \& Del Rey, R. (2012). European bullying intervention project questionnaire (EBIPQ). University of bologna. https://doi.org/10.1037/t66195-000

16. Butt, S. S., Jamil, F., \& Khalid, R. (2019). Cyberbullying, self-esteem and interpersonal trust in young adults. Pakistan Journal of Social and Clinical Psychology, 17(1), 38-46.

17. Calvete, E., Orue, I., Estévez, A., Villardón, L., \& Padilla, P. (2010). Cyberbullying in adolescents: Modalities and aggressors' profile. Computers in Human Behavior, 26(5), 1128-1135. https://doi.org/10.1016/j.chb.2010.03.017

18. Campbell, M. A. (2005). Cyber bullying: An old problem in a new guise? Australian journal of Guidance and Counselling, 15(1), 68-76. https://doi.org/10.1375/ajgc.15.1.68

19. Carney, A. G., \& Merrell, K. W. (2001). Bullying in schools: Perspectives on understanding and preventing an international problem. School Psychology International, 22(3), 364-382. https://doi.org/10.1177/0143034301223011

20. Carrington, S., Campbell, M., Saggers, B., Ashburner, J., Vicig, F., Dillon-Wallace, J., \& Hwang, Y.-S. (2017). Recommendations of school students with autism spectrum disorder and their parents in regard to bullying and cyberbullying prevention and intervention. International Journal of Inclusive Education, 21(10), 1045-1064. https://doi.org/10.1080/13603116.2017.1331381

21. Cénat, J. M., Hébert, M., Blais, M., Lavoie, F., Guerrier, M., \& Derivois, D. (2014). Cyberbullying, psychological distress and self-esteem among youth in Quebec schools. Journal of affective disorders, 169, 7-9. https://doi.org/10.1016/j.jad.2014.07.019

22. Choi, K.-S., Earl, K., Lee, J. R., \& Cho, S. (2019). Diagnosis of cyber and non-physical bullying victimization: A lifestyles and routine activities theory approach to constructing effective preventative measures. Computers in Human Behavior, 92, 11-19. https://doi.org/10.1016/j.chb.2018.10.014

23. Cook, C. R., Williams, K. R., Guerra, N. G., \& Kim, T. (2009). Variability in the prevalence of bullying and victimization. Handbook of bullying in schools: An international perspective, 347-362.

24. Corcoran, L., Guckin, C. M., \& Prentice, G. (2015). Cyberbullying or cyber aggression?: A review of existing definitions of cyber-based peer-to-peer aggression. Societies, 5(2), 245-255. https://doi.org/10.3390/soc5020245

25. Corvo, K. (2010). Towards an integrated theory of relational violence: Is bullying a risk factor for domestic violence? Aggression and Violent Behavior, 15(3), 181-190. https://doi.org/10.1016/j.avb.2009.12.001

26. Crowe, T. V. (2003). Self-esteem scores among deaf college students: an examination of Gender and parents' hearing status and signing ability. Journal of Deaf Studies and Deaf Education, 8(2), 199-206. https://doi.org/10.1093/deafed/eng003

27. Crowe, T. V. (2003). Self-Esteem Scores Among Deaf College Students: An Examination of Gender and Parents' Hearing Status and Signing Ability. The Journal of Deaf Studies and Deaf Education, 8(2), 199-206. https://doi.org/10.1093/deafed/eng003

28. Dadic, B. (2014). The relationship between adolescent's views of cyber-bulling and their self-esteem levels. Southern Connecticut State University.

29. Del Rey, R., Casas, J. A., Ortega-Ruiz, R., Schultze-Krumbholz, A., Scheithauer, H., Smith, P., Thompson, F., Barkoukis, V., Tsorbatzoudis, H., Brighi, A., Guarini, A., Pyżalski, J., \& Plichta, P. (2015). Structural validation and cross-cultural robustness of the European Cyberbullying Intervention Project Questionnaire. Computers in Human Behavior, 50, 141-147. https://doi.org/10.1016/j.chb.2015.03.065

30. Dembo, R., Krupa, J. M., Faber, J., DiClemente, R. J., Wareham, J., \& Schmeidler, J. (2019). An Examination of Gender Differences in Bullying among Justice-involved Adolescents. Deviant Behavior, 1-20. https://doi.org/10.1080/01639625.2019.1666608

31. Ghiamatyoon, N., Nesayan, A., \& Movallali, G. (2016). The cyberspace usage in students with hearing impairment and their motivations and their feeling of loneliness. Auditory and Vestibular Research, 25(4), 234-240.

32. Greene, M. B. (2006). Bullying in schools: A plea for measure of human rights. Journal of Social Issues, 62(1), 6379. https://doi.org/10.1111/j.1540-4560.2006.00439.x

33. Hadjikakou, K., \& Panayiotis, P. (2012). Bullying and cyberbullying and deaf and hard of hearing children: A review of the literature. International Journal on Mental Health and Deafness, 2(1), 18-32.

34. Hale, R., Fox, C. L., \& Murray, M. (2017). "As a Parent You Become a Tiger": Parents Talking about Bullying at School. Journal of Child and Family Studies, 26(7), 2000-2015. https://doi.org/10.1007/s10826-017-0710-z

35. Hammad, M. A. (2016). Future Anxiety and Its Relationship to Students' Attitude toward Academic Specialization. Journal of Education and Practice, 7(15), 54-65.

36. Hammad, M. A., \& Awed, H. S. M. (2016). Social Information Processing and Reactive and Proactive Aggression among Children with ADHD. International Journal of Psychological Studies, 8(2), 111-119. ttps://doi.org/10.5539/ijps.v8n2p111 
37. Harper, M.-G. (2019). Tolerable Deviance and How it Applies to Cyberbullying. Deviant Behavior, 40(1), 29-39. https://doi.org/10.1080/01639625.2017.1411023

38. Hesapçioğlu, S. T., Meraler, H. Y., \& Ercan, F. (2018). Bullying in schools and its relation with depressive symptoms, self-esteem, and suicidal ideation in adolescents. Anadolu Psikiyatri Dergisi, 19(2), 210-216. https://doi.org/10.5455/apd.268900

39. Hillsberg, C., \& Spak, H. (2006). Young adult literature as the centerpiece of an anti-bullying program in middle school. Middle School Journal, 38(2), 23-28. https://doi.org/10.1080/00940771.2006.11461570

40. Hinduja, S., \& Patchin, J. (2010). Cyberbullying research summary: Cyberbullying and self-esteem. Cyberbullying Research Center. Retirado em, 27.

41. Hinduja, S., \& Patchin, J. W. (2010). Bullying, cyberbullying, and suicide. Archives of suicide research, 14(3), 206221. https://doi.org/10.1080/13811118.2010.494133

42. Hinduja, S., \& Patchin, J. W. (2019). Connecting adolescent suicide to the severity of bullying and cyberbullying. Journal of school violence, 18(3), 333-346. https://doi.org/10.1080/15388220.2018.1492417

43. Huang, Y.-y., \& Chou, C. (2010). An analysis of multiple factors of cyberbullying among junior high school students in Taiwan. Computers in Human Behavior, 26(6), 1581-1590. https://doi.org/10.1016/j.chb.2010.06.005

44. Huffman, A. H., Whetten, J., \& Huffman, W. H. (2013). Using technology in higher education: The influence of gender roles on technology self-efficacy. Computers in Human Behavior, 29(4), 1779-1786. https://doi.org/10.1016/j.chb.2013.02.012

45. Humphrey, N., \& Hebron, J. (2015). Bullying of children and adolescents with autism spectrum conditions: A 'state of the field' review. International Journal of Inclusive Education, 19(8), 845-862. https://doi.org/10.1080/13603116.2014.981602

46. Hussein, M. H. (2010). The peer interaction in primary school questionnaire: Testing for measurement equivalence and latent mean differences in bullying between Gender in Egypt, Saudi Arabia and the USA. Social Psychology of Education, 13(1), 57-76. https://doi.org/10.1007/s11218-009-9098-y

47. Hwang, Y.-S., Dillon-Wallace, J., Campbell, M., Ashburner, J., Saggers, B., Carrington, S., \& Hand, K. (2018). How students with autism spectrum conditions understand traditional bullying and cyberbullying. International Journal of Inclusive Education, 22(4), 391-408. https://doi.org/10.1080/13603116.2017.1370736

48. Jambor, E., \& Elliott, M. (2005). Self-esteem and Coping Strategies among Deaf Students. The Journal of Deaf Studies and Deaf Education, 10(1), 63-81. https://doi.org/10.1093/deafed/eni004

49. Jani, R., Alias, A. A., \& Tumin, M. (2020). Persons with disabilities' education and quality of life: evidence from Malaysia. International Journal of Inclusive Education, 1-13. https://doi.org/10.1080/13603116.2020.1726511

50. Kobosko, J., Jedrzejczak, W. W., Gos, E., Geremek-Samsonowicz, A., Ludwikowski, M., \& Skarzynski, H. (2018). Self-esteem in the deaf who have become cochlear implant users as adults. PLoS One, 13(9), e0203680. https://doi.org/10.1371/journal.pone.0203680

51. Kogovšek, D. (2015). HASH (0xbcc3ef10). Journal of special education and rehabilitation, 16(3-4), 30-51. https://doi.org/10.1515/jser-2015-0010

52. Koh, J.-B., \& Wong, J. S. (2017). Survival of the fittest and the sexiest: Evolutionary origins of adolescent bullying. Journal of interpersonal violence, 32(17), 2668-2690. https://doi.org/10.1177/0886260515593546

53. Kowalski, R. M., \& Limber, S. P. (2013). Psychological, physical, and academic correlates of cyberbullying and traditional bullying. Journal of Adolescent Health, 53(1), S13-S20. https://doi.org/10.1016/j.jadohealth.2012.09.018

54. Lee, J., Cheon, Y. M., Wei, X., \& Chung, G. H. (2018). The Role of Ethnic Socialization, Ethnic Identity and SelfEsteem: Implications for Bi-ethnic Adolescents' School Adjustment. Journal of Child and Family Studies, 27(12), 3831-3841. https://doi.org/10.1007/s10826-018-1235-9

55. Lee, J. M., Hong, J. S., Yoon, J., Peguero, A. A., \& Seok, H. J. (2018). Correlates of adolescent cyberbullying in South Korea in multiple contexts: A review of the literature and implications for research and school practice. Deviant Behavior, 39(3), 293-308. https://doi.org/10.1080/01639625.2016.1269568

56. Lee, M.-A., Shin, C., \& Kang, J.-H. (2019). How the popularity of bullies influences the self-esteem of their classmates: a study of first-year middle school students in South Korea. Journal of interpersonal violence, 0886260519870164. https://doi.org/10.1177/0886260519870164

57. Lei, H., Mao, W., Cheong, C. M., Wen, Y., Cui, Y., \& Cai, Z. (2019). The relationship between self-esteem and cyberbullying: A meta-analysis of children and youth students. Current Psychology, 1-13.

58. Maiano, C., Aime, A., Salvas, M. C., Morin, A. J. S., \& Normand, C. L. (2016). Prealence and correlates of bullying perpetration and victimization among school-aged youth with intellectual disabilities: A systematic reviewv. Research in developmental disabilities, 49-50, 181-195. https://doi.org/10.1016/j.ridd.2015.11.015

59. Mann, M. M., Hosman, C. M., Schaalma, H. P., \& De Vries, N. K. (2004). Self-esteem in a broad-spectrum approach for mental health promotion. Health education research, 19(4), 357-372. https://doi.org/10.1093/her/cyg041 
60. Mousavi, S. Z., Movallali, G., \& Nare, N. M. (2017). Adolescents with deafness: a review of self-esteem and its components. Auditory and Vestibular Research, 26(3), 125-137.

61. Movallali, G., Ashori, M., Jalil-Abkenar, S., \& Salehy, Z. (2014). Effect of life skills training on social skills of hearing impaired students. IOSR Journal of Research and Methods in Education, 4(5), 28-34. https://doi.org/10.9790/7388-04522834

62. Mulat, M., Lehtomäki, E., \& Savolainen, H. (2019). Academic achievement and self-concept of deaf and hard-ofhearing and hearing students transitioning from the first to second cycle of primary school in Ethiopia. International Journal of Inclusive Education, 23(6), 609-623. https://doi.org/10.1080/13603116.2018.1441913

63. Nouran, H. F. (2015). Teachers' knowledge about bullying in elementary schools in Saudi Arabia State University of New York ]. New York.

64. Olweus, D. (2012). Cyberbullying: An overrated phenomenon? European journal of developmental psychology, 9(5), 520-538. https://doi.org/10.1080/17405629.2012.682358

65. Palermiti, A. L., Servidio, R., Bartolo, M. G., \& Costabile, A. (2017). Cyberbullying and self-esteem: An Italian study. Computers in Human Behavior, 69, 136-141. https://doi.org/10.1016/j.chb.2016.12.026

66. Patchin, J. W., \& Hinduja, S. (2010). Cyberbullying and self-esteem. Journal of school health, 80(12), 614-621. https://doi.org/10.1111/j.1746-1561.2010.00548.x

67. Peluchette, J. V., Karl, K., Wood, C., \& Williams, J. (2015). Cyberbullying victimization: Do victims' personality and risky social network behaviors contribute to the problem? Computers in Human Behavior, 52, 424-435. https://doi.org/10.1016/j.chb.2015.06.028

68. Peplau, L. A., Veniegas, R. C., Taylor, P. L., \& DeBro, S. C. (1999). Sociocultural perspectives on the lives of women and men. In Gender, culture, and ethnicity: Current research about women and men. (pp. 23-37). Mayfield Publishing Co.

69. Pinquart, M., \& Pfeiffer, J. P. (2015). Bullying in students with and without hearing loss. Deafness \& Education International, 17(2), 101-110. https://doi.org/10.1179/1557069X14Y.0000000044

70. Raskauskas, J., \& Modell, S. (2011). Modifying anti-bullying programs to include students with disabilities. Teaching exceptional children, 44(1), 60-67. https://doi.org/10.1177/004005991104400107

71. Rosenberg, M. (1965). Society and the adolescent self-image Princeton, NJ: Princeton Univer. Press. Google Scholar| Crossref.

72. Salmivalli, C., Kaukiainen, A., Kaistaniemi, L., \& Lagerspetz, K. M. (1999). Self-evaluated self-esteem, peerevaluated self-esteem, and defensive egotism as predictors of adolescents' participation in bullying situations. Personality and social psychology bulletin, 25(10), 1268-1278. https://doi.org/10.1177/0146167299258008

73. Smith, P. K. (1997). Bullying in Life-Span Perspective: What Can Studies of School Bullying. Journal of Community \& Applied Social Psychology, 7, 249-255. https://doi.org/10.1002/(SICI)10991298(199706)7:3<249::AID-CASP425>3.0.CO;2-2

74. Smith, P. K. (2012). Cyberbullying: Challenges and opportunities for a research program-A response to Olweus (2012). European journal of developmental psychology, 9(5), $\quad$ 553-558. https://doi.org/10.1080/17405629.2012.689821

75. Smith, P. K., Ananiadou, K., \& Cowie, H. (2003). Interventions to reduce school bullying. The Canadian Journal of Psychiatry, 48(9), 591-599. https://doi.org/10.1177/070674370304800905

76. Smith, P. K., Catalano, R., JUNGER-TAS, J. J., SLEE, P. P., MORITA, Y., \& OLWEUS, D. (1999). The nature of school bullying: A cross-national perspective. Psychology Press.

77. Theunissen, S. C., Rieffe, C., Netten, A. P., Briaire, J. J., Soede, W., Kouwenberg, M., \& Frijns, J. H. (2014). Selfesteem in hearing-impaired children: the influence of communication, education, and audiological characteristics. PloS one, 9(4), e94521. https://doi.org/10.1371/journal.pone.0094521

78. Twardowska-Staszek, E., Zych, I., \& Ortega-Ruiz, R. (2018). Bullying and cyberbullying in Polish elementary and middle schools: Validation of questionnaires and nature of the phenomena. Children and Youth Services Review, 95, 217-225. https://doi.org/10.1016/j.childyouth.2018.10.045

79. Víllora, B., Navarro, R., \& Yubero, S. (2019). The role of social-interpersonal and cognitive-individual factors in cyber dating victimization and perpetration: comparing the direct, control, and combined forms of abuse. Journal of interpersonal violence, 0886260519851172 . https://doi.org/10.1177/0886260519851172

80. Wade, A. T., Wade, C., Tavris, W., Tavris, C., \& Hall, P. (2006). Psychology \& Live! Psych Experiments and Simulations Package. Pearson College Division. https://books.google.com.sa/books?id=oPbWAAAACAAJ

81. Wang, P., Wang, X., \& Lei, L. (2019). Gender Differences Between Student-Student Relationship and Cyberbullying Perpetration: An Evolutionary Perspective. Journal of interpersonal violence, 0886260519865970. https://doi.org/10.1177/0886260519865970

82. Weiner, M. T., Day, S. J., \& Galvan, D. (2013). Deaf and hard of hearing students' perspectives on bullying and school climate. American Annals of the Deaf, 158(3), 334-343. https://doi.org/10.1353/aad.2013.0029 
83. Wolke, D., \& Sapouna, M. (2008). Big men feeling small: Childhood bullying experience, muscle dysmorphia and other mental health problems in bodybuilders. Psychology of Sport and Exercise, 9(5), 595-604. https://doi.org/10.1016/j.psychsport.2007.10.002 